processen, zum Heizen von Dampfkesseln und zu Destillationen und zu Abdampfungen ganz gut zu brauchen sein.

Noch muss ich darauf aufmerksam machen, dass die Auffindung von ächtem Asphalte am Kaukasus den Beweis liefert, dass die Naphtha der dortigen Quellen nicht blos Neftedegil-Naphtha ist, sondern, dass auch Asphalt-Naphtha vorkommt. Es wird dadurch zweifelhaft, ob die Kir genannte Substanz auch stets mit dem Neftedegil identisch sei. Es wäre daher wünschenswerth, dass der Kir aus den Gruben der Umgebungen von Baku einer chemischen Untersuchung unterworfen würde, um diesen Punkt in's Klare zu bringen.

\title{
XLVI.
}

\section{Untersuchung eines bei Mainz gefundenen Meteorsteins.}

\author{
Von \\ Ferdinand Seelheim, \\ Assistent am chemischen Laboratorium zu Wiesbaden.
}

(Aus d. Jahrb. des Vereins für Naturkunde im Herzogthum Nassau Heft XII.)

Der Meteorstein, dessen Analyse ich nachstehend mittheile, wurde mir von Herrn Dr. Gergens in Mainz, welcher denselben aufgefunden hat, zugestellt. Herr Dr. Gergens theilte mir darüber Folgendes mit:

„Vor einigen Jahren wurde auf der Anhöhe oberhalb Mainz in der Nähe der Pariser Chaussee beim Umpflügen eines Ackers in kalkhaltigem Boden ein Stein gefunden, welchen man für Erz hielt und mir endlich zur näheren Untersuchnng brachte. Dieser Stein mochte damals etwa $31 / 2$ Pfunde wiegen, und hatte äusserlich das Ansehen eines eisenhaltigen stark verwitterten Dolerites, hier und da mit neu entstandener Kruste kalkhaltigen Brauneisensteins überzogen. Von einer Rinde mit Ausnahme der später 
durch Oxydation erzeugten, ist nichts zu bemerken; was man dafür halten könnte, ist wohl nur durch Reibung geglättet. Der Stein ist offenbar ein Bruchstück eines weit grösseren Meteoriten, und hatte, als er mir gebracht wurde, scharfkantige Ecken.

Das specifische Gewicht des ganzen Steins betrug 3,44. Beim Zerschlagen zeigte sich die Verwitterung bis in das Innere des Steins vorgedrungen, nur einzelne dichtere Parthieen, etwa die Hälfte der ganzen Masse, waren noch wenig zersetzt, dunkelbraun und zeigten dunkelstahlgraue metallglänzende Klümpchen von unregelmässig geflossener Gestalt und in der sehr festen dunkelbraunen Masse des Steines eine Menge blättrig krystallinischer metallischer Flitterchen. Alle metallglänzenden Parthien sind dem Magnete folgsam, ziehen das Eisen aber nicht an und erhalten in Chlorkupferlösung einen Ueberzug von metallischem Kupfer. Das verwitterte Silikat hat grosse Aehnlichkeit mit einem stark zersetzten Olivin, ist schmutzig gelblichbraun, die festen Körner olivengrün, körnig; hier und da sind einzelne weniger zersetzte Körner zu bemerken, welche durch undeutliche Blätterdurchgänge, graue Farbe und matten, fettigen Glasglanz einige Aehnlichkeit mit Labrador haben.

Die am wenigsten verwitterten dichteren Theile sind bräunlich-schwarz, werden nach aussen hin allmählich dunkelgelblichbraun; ihr Bruch ist im Grossen ziemlich muschlich, im Kleinen splittrig, in feinen Splitterchen an den dunkelsten schwarzbraunen Stellen undurchsichtig, an den gelblichbraunen, an welchen offenbar die Zersetzung: schon begonnen hat, hyazinthroth durchscheinend, allenthalben erfüllt mit den oben beschriebenen metallischen Flitterchen. Es fanden sich auch einige metallische Körnchen, welche die Grösse einer halben Erbse erreichten, in sehr unregelmässigen kaum etwas grösseren Blasenräumen steckten und wie gesagt eine deutlich geflossene Oberfläche haben.

Diese Metallverbindung (Phosphornickeleisen) ist muschlich im Bruch, spröde und in den Blasenräumen mit dünner lauchgrüner erdiger Rinde überzogen. 
An einer Stelle des am wenigsten zersetzten Gesteines sitzen in einer kleinen Spalte sehr feine perlmutterglänzende lauchgrüne Blättchen, ähnlich dem Chloritoid; an an einer anderen, in einem alten Sprunge, ein dünner Ueberzug, den ich nach Härte, Glanz und Verhalten gegen Salzsäure für später eingedrungenen Gyps halte, was bei dem Gypsgehalte des Bodens, in welchem der Stein vielleicht schon Jahrhunderte eingebettet war, nicht auffallend ist."

Die zur Analyse verwendeten Stücke gehörten dem inneren am wenigsten zersetzten Theile an und bestanden in unbestimmt eckigen, wenig stumpfkantigen Bruchstücken mit unebener Oberfiäche, auf der sich überall die theils fein eingesprengten, theils in feinen Körnern auftretenden metallglänzenden grösstentheils stahlgrauen Partikelchen zeigten.

Das specifische Gewicht ist 3,26. (Das von Herrn Dr. Gergens gefundene bezieht sich auf den ganzen Stein.) Die Härte ist ungefähr gleich der des Apatits. Vor dem Löthrohr runden sich die Kanten $a b$.

Was die Farbe und Durchsichtigkeit betrifft, so füge ich dem ron Herrn Dr. Gergens hierüber Mitgetheilten noch hinzu, dass das Pulver, welches sich sonst nur durch eine hellere Schattirung unterscheidet, unter dem Mikroskope bei mässiger Vergrösserung hauptsächlich aus durchsichtigen und durchscheinenden Stücken von grünlichgelber bis brauner Farbe besteht, unter denen hin und wieder auch wasserbelle, sowie die unten angeführten accessorischen Bestandtheile vorkommen.

Beim Behandeln mit Salzsäure entwickelt sich eine geringe Menge Wasserstoffgas, dem eine Spur Schwefelwasserstoff beigemengt ist, durch Bleipapier nachweisbar.

Durch diese Behandlung wird der Stein in zwei Silikate zerlegt, in ein zersetzbares, dessen Lösung etwas gelblich gefärbt ist, und nach kurzem Stehen gelatinirt, und in ein unlösliches, welches sich als graues Pulver zu Boden setzt. 
Der zur quantitativen Analyse eingeschlagene Weg war folgender:

Ein Theil des feinen gut gemischten Pulvers wurde mit starker Salzsäure längere Zeit erwärmt, das Ganze im Wasserbade zur Trockne gebracht und anhaltend einer Temperatur von $100^{\circ}$ ausgesetzt zur Abscheidung der Kieselsäure.

In der von Kieselsäure befreiten Lösung mussten zunächst Eisen, Nickel und Magnesia bestimmt werden. Nachdem vorher durch Schwefelwasserstoff unter gelinder Erwärmung kleine Mengen von Kupfer und Zinn ausgeschieden waren, wurde mit Salpetersäure oxydirt und das Eisen durch zweimaliges Fällen mit kohlensaurem Baryt und Auswaschen mit Kohlensäure haltendem Wasser vom Nickel getrennt, das Nickel nach der Entfernung des Baryts mit farblosem Schwefelammonium niedergeschlagen, in Nickeloxydul übergeführt und als solches gewogen. Im durch Eindampfen concentrirten Filtrate konnte die Magnesia, da kein Kalk vorhanden war, direct mit phosphorsaurem Natron und Ammon ausgeschieden werden.

Der nach dem Verdampfen mit Salzsäure ungelöst gebliebene Antheil wurde von der Kieselsäure des zersetzbaren Silikates durch Behandeln mit kohlensaurem Natron befreit.

Um die Gewichtsmenge der Bestandtheile des durch Salzsäure nicht zersetzbaren Silikates zu ermitteln, schien es mir am gerathensten, den ursprünglichen Stein zu benutzen.

Es wurde zu dem Ende eine Portion mit kohlensaurem Natron-Kali und Salpeter aufgeschlossen, die Schmelze mit Salpetersäure behandelt, die Kieselsäure abgeschieden und durch Anwendung desselben Verfahrens, wie bei der Analyse des löslichen Silikates, ein Niederschlag durch kohlensauren Baryt erhalten, der das gesammte Eisen, die Thonerde und die sogleich zu erwähnende Phosphorsäure enthielt. Nachdem derselbe in Salzsäure gelöst, und der Baryt mit Schwefelsäure ausgefällt worden war, ergab sich die Gesammtmenge dieser drei Bestandtheile als 
Ammonniederschlag, dessen Eisengehalt durch Titriren mit übermangansaurem Kali, die Thonerde nach Abzug der Phosphorsäure aus der Differenz gefunden wurde.

Endlich geschah die Bestimmung des, einen Bestandtheil ausmachenden, Kalis durch Aufschliessen mit Fluorwasserstoff, Ausfällen mit reiner Kalkmilch und nach wiederholtem Fällen mit kohlensaurem Ammon durch Ueberführung in schwefelsaures Kali.

Es bleiben jetzt noch die als fremdartige Beimengungen anzusehenden Bestandtheile übrig, deren Bestimmungsmethoden ebenfalls noch eine kurze Erwähnung finden mögen.

Für die Ermittlung des Chroms wählte ich die Methode von P. Hart durch Schmelzen mit Borax etc. (S. dies. Journ. LXVII, 320.) Die hierbei aus dem beigemengten Schwefelkies gebildete Schwefelsäure musste, behufs der Ueberführung der Chromsäure in chromsaures Bleioxyd, zuvor mittels Strontianlösung abgeschieden werden.

Die einen weiteren Gemengtheil ausmachende Phosphorsäure lieferte in einer durch verdünnte Salzsäure und in einer durch Königswasser erhaltenen Lösung, nach der Sonnenschein'schen Methode, hinlänglich genau übereinstimmende Resultate, so dass die Abwesenheit einer wägbaren Menge unoxydirten Phosphors hierdurch dargethan ist.

Der Schwefel ist so gut wie ganz als Schwefelkies in diesem Meteoriten enthalten, da, wenn Einfach-Schwefeleisen vorhanden wäre, die Schwefelwasserstoffentwicklung beträchtlicher gewesen sein würde; präformirte Schwefelsäure fand sich nicht. Die Gewichtsbestimmung wurde in einer Königswasserlösung vorgenommen.

Schliesslich wurde noch der Wassergehalt durch Glühen im trocknen Luftstrome und Auffangen des Wassers im Chlorcalciumrohr ermittelt.

Die ganze Analyse führte ich mit bei $100^{\circ}$ getrocknetem Meteorstein aus. 
240 Seelheim: Untersuchung eines gefundenen Meteorsteins.

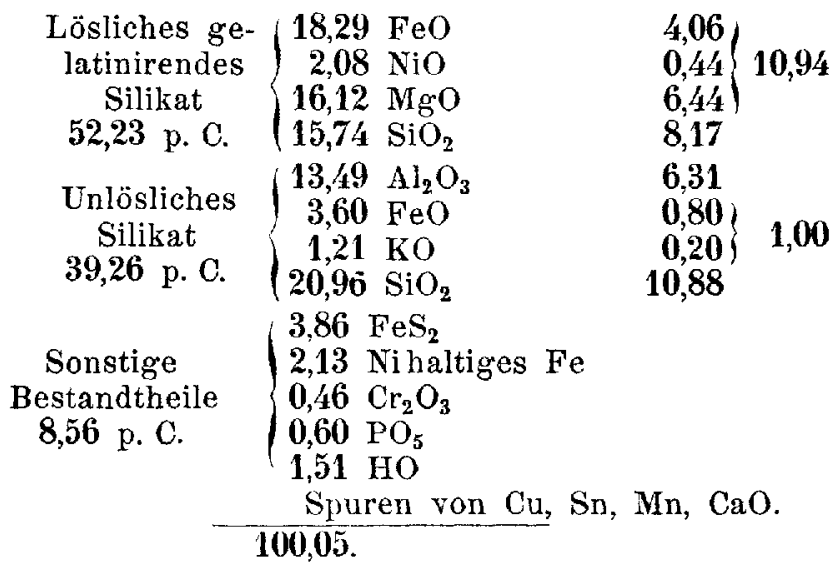

Berechnet man aus den Sauerstoffverhältnissen Formeln, so erhält man für das unlösliche Silikat $2\left(\mathrm{R}_{2} \mathrm{O}_{3}, 2 \mathrm{SiO}_{2}\right)$ $+\mathrm{RO}, \mathrm{SiO}_{2}$. Dieser entspricht das Sauerstoffverhältniss $6: 1: 10$.

Zieht man den kleinen Rest der Kieselsäure mit zum löslichen Silikat, so erhält man annährend die Formel 2RO, $\mathrm{SiO}_{2}$. Dasselbe giebt sich mithin als Olivin zu erkennen. Diese Formel wird noch wahrscheinlicher, wenn man bedenkt, dass der kleine Ueberschuss von RO daher kommt, dass das Eisen hier als Oxydul berechnet ist, während doch ein kleiner Theil als Oxyd darin enthalten ist, der indessen nicht näher bestimmt werden konnte.

Der als Nickel enthaltendes Eisen aufgeführte Bestand theil ist durch den Magneten ausgezogen. Er stellte zum Theil metallglänzende stahlgraue feine Körner, die sich beim Hämmern ganz wenig abplatten liessen, theils schwarze schwammige Massen dar, war vollständig unter Wasserstoffentwicklung in Salzsäure löslich.

Er wurde qualitativ untersucht, und bestand grösstentheils aus Eisen, aus wenig Nickel und einer Spur Phosphor. 